\title{
Oncocytoma of the eyelid: a case report
}

\author{
V T THALlER, J R O COLLIN, AND A C E McCARTNEY \\ From Moorfields Eye Hospital, High Holborn, London WCIV 7AN
}

SUMMARY Oncocytic tumours of the eyelids are rare, only one previous case having been reported. This paper describes a second such lid tumour affecting the medial upper lid. We present the clinical features, surgical management, and histology of the lesion.

Oncocytomas are benign adenomatous tumours composed of oncocytes, a name coined by Hamperl.' These tumours have also been called oxyphilic adenomas. Oncocytic tumours of the ocular adnexae are rare, such a lesion having first been reported by Radnót ${ }^{2}$ in 1941. The lesion he described involved the lacrimal sac. The total number of oncocytomas of the ocular adnexae so far reported in the world literature is 34 . Of these only one other case involved the eyelid.

We report here a second case of an oncocytoma involving an eyelid.

\section{Case report}

A 67-year-old man presented in 1981 with a five-year history of a slowly enlarging right upper eyelid mass. It was reddish in colour, occupied the medial onethird of the lid, and tended to fluctuate in size. The tumour surrounded the upper canaliculus and caused pouting of the punctum but did not involve the caruncle. A biopsy was performed, and the tumour was found to be an oncocytoma. It was treated with radiotherapy (3750 rad in five fractions over three weeks). This produced no noticeable response. The patient was then referred to the Moorfields Oculoplastic Unit for further management. Unfortunately he was also found to have thoracic, abdominal, and femoral aneurysms which required aortofemoral grafting. As this took priority he did not come to us again until 1985 . Over the intervening period the tumour had increased by only about $1 \mathrm{~mm}$ in size, measuring $6 \times 8 \mathrm{~mm}$ in diameter (Fig. 1). It was smooth and of a dark reddish hue, this being more clearly apparent on the subtarsal surface (Figs. 2A, 2B).

The tumour was removed under local anaesthesia as a full-thickness, pentagonal lid resection incorpo-

Correspondence to Dr V T Thaller. rating a $2 \mathrm{~mm}$ clear skin margin. The upper lacrimal canaliculus was sacrificed in the process, leaving a large defect which comprised almost half the total eyelid length (Fig. 3). A primary closure of the lid defect was achieved by performing an upper limb lateral cantholysis, freeing the orbital septum, and suturing the cut medial end of the remaining tarsal plate to the posterior limb of the medial canthal tendon. The orbicularis muscle and skin were closed directly. This procedure produced a comfortable and cosmetically satisfactory result (Fig. 4). During a follow-up of nine months the patient remained asymptomatic.

\section{HISTOLOGY}

Paraffin sections of the specimen showed that the tumour was composed of several lobules and nodules which contained anastomosing cords and islets of eosinophilic cells with glandular spaces and focal ducts filled with eosinophilic debris (Fig. 5). The tumour cells were large, polygonal, and contained abundant granular cytoplasm. The nuclei were rounded or oval, regularly arranged, with prominent

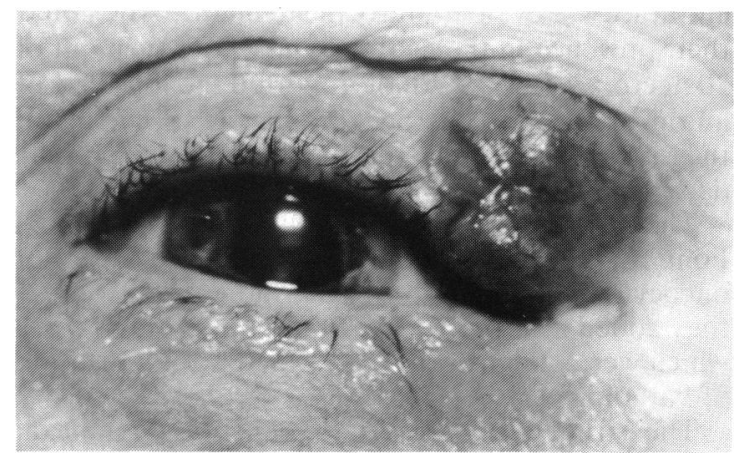

Fig. 1 Oncocytoma of the right upper eyelid, involving the upper lacrimal punctum. 

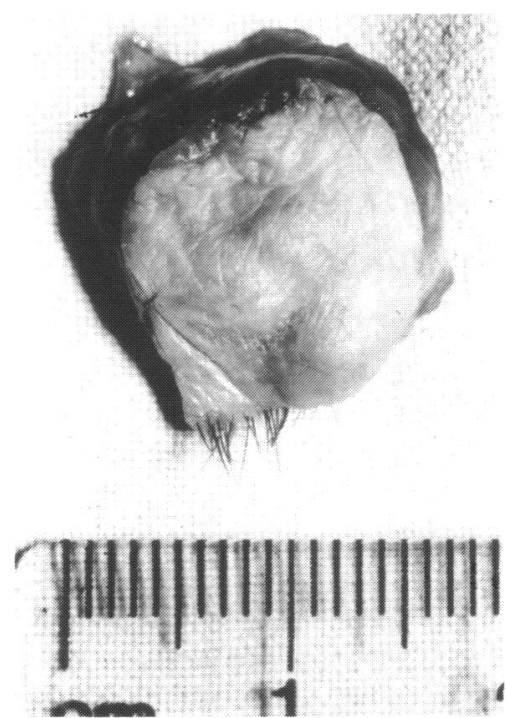

Fig. 2A Skinsurface of excised tumour specimen.

nucleoli (Figs. 5, 6). The tumour occupied almost the full thickness of the lid, ulcerating on the conjunctival side and causing attenuation of the overlying epidermis on the skin side. The microscopic features were consistent with the diagnosis of oncocytoma (oxyphilic adenoma).

\section{Discussion}

The term oncocytoma refers to tumours composed of large eosinophilic cells (oncocytes) growing in an adenomatous pattern. Oncocytomas are most commonly found in salivary glands but have been described in the thyroid, parathyroid, pituitary and adrenal glands, and also in the kidney, testes, pharynx, larynx, and trachea.

The first mention of oncocytes in the ophthalmic literature was by Böck and Schlagenhauff, "who noted their presence in the lacrimal glands of seven out of 20 necropsy cases. Radnót ${ }^{2}$ reported the first case of an oncocytoma of the ocular adnexae, occurring in the rear sac wall in a 66-year-old woman with chronic dacryocystitis.

The existing literature was reviewed by Biggs and Font ${ }^{+}$in 1977 and totalled 17 reported cases of oncocytoma affecting the ocular adnexae. To these they added a further 17 previously unreported cases which were on file at the US Armed Forces Institute of Pathology.

The caruncle is the site of predeliction for adnexal oncocytomas, accounting for $56 \%$ of reported cases, with the lacrimal sac coming second $(24 \%)$.
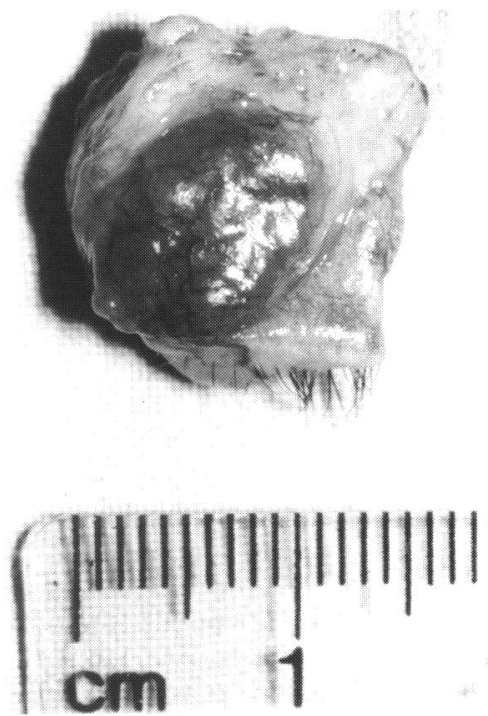

Fig. 2B Conjunctival surface of the excised tumour specimen.

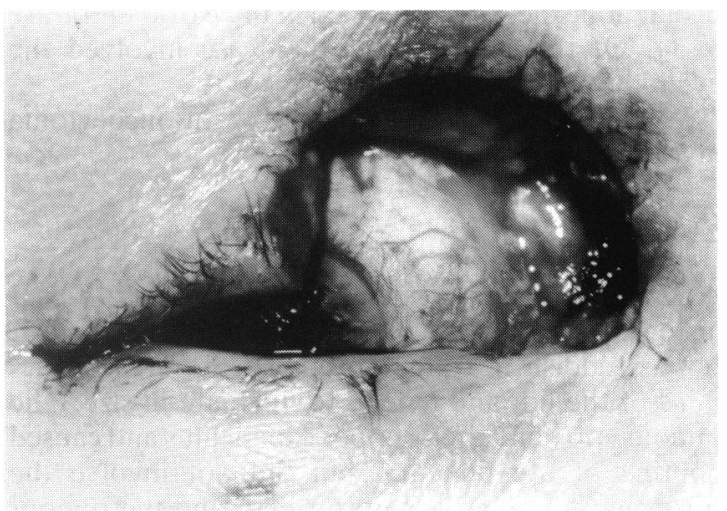

Fig. 3 Right upper lid defect resulting from the tumour excision (and part of the upper lacrimal canaliculus).

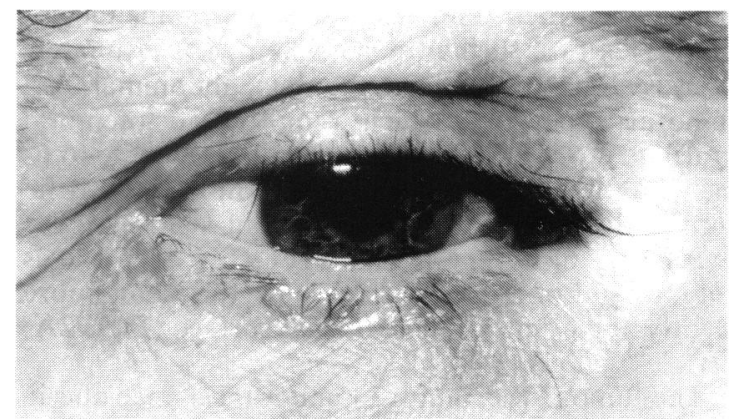

Fig. 4 Reconstructed right upper lid four months after excision of oncocytoma. 


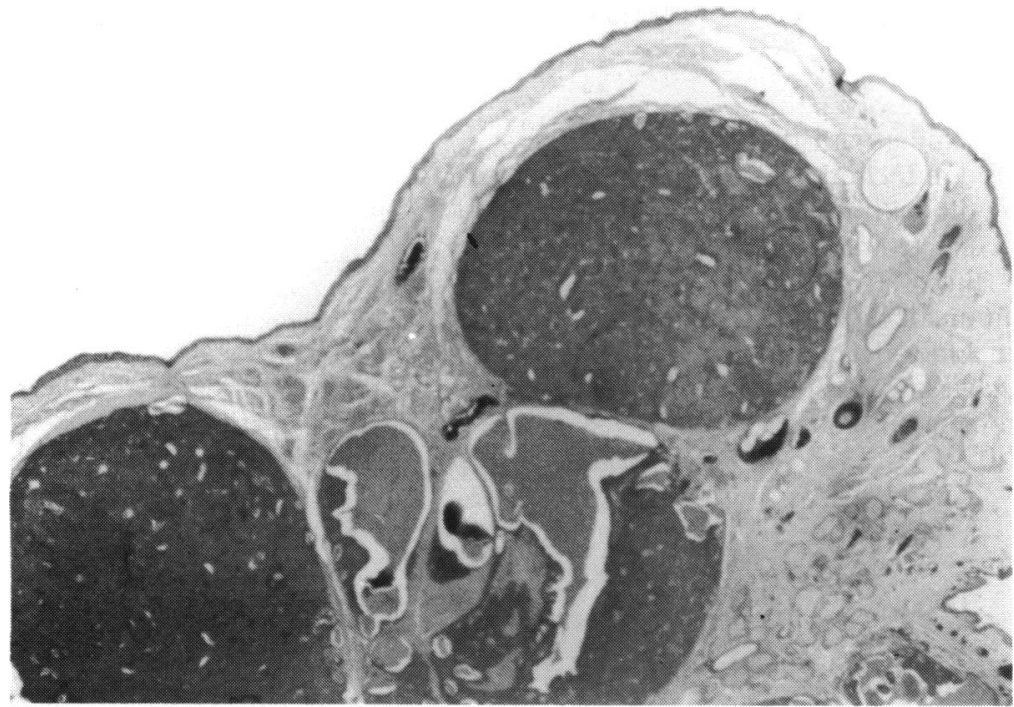

Fig. 5 Oncocytoma of eyelid. Rounded nodules of tumour and adjacent dilated ducts filled with eosinophilic debris, lying in dermis. Haematoxylin and eosin.

Only one case of lid involvement with an oncocytoma has previously been reported, and to this we add our case. The diagnosis was made on biopsy, though the lesion did display the characteristic cherry red colour previously noted in caruncular tumours. This was particularly obvious on the conjunctival surface when the lid was everted. The slow growth and smooth contour are further pointers to the diagnosis. The eyelid as the tumour site does not present any special management problems. Our case did not improve following radiotherapy, and therefore the treatment of choice would appear to be complete surgical excision with primary repair of the resulting defect, according to the conventional principles of lid closure and reconstruction.

In spite of the frequent occurrence of oncocytes in the lacrimal gland, this is a rare site for oncocytic tumour formation. ${ }^{3}$ When they occur they may be malignant, two of the three reported lacrimal gland tumours being oncocytic adenocarcinomas. In general, though, oncocytomas run a slow and benign course.

The origin of oncocytes remains a matter of some debate. They seem to occur in aged individuals,

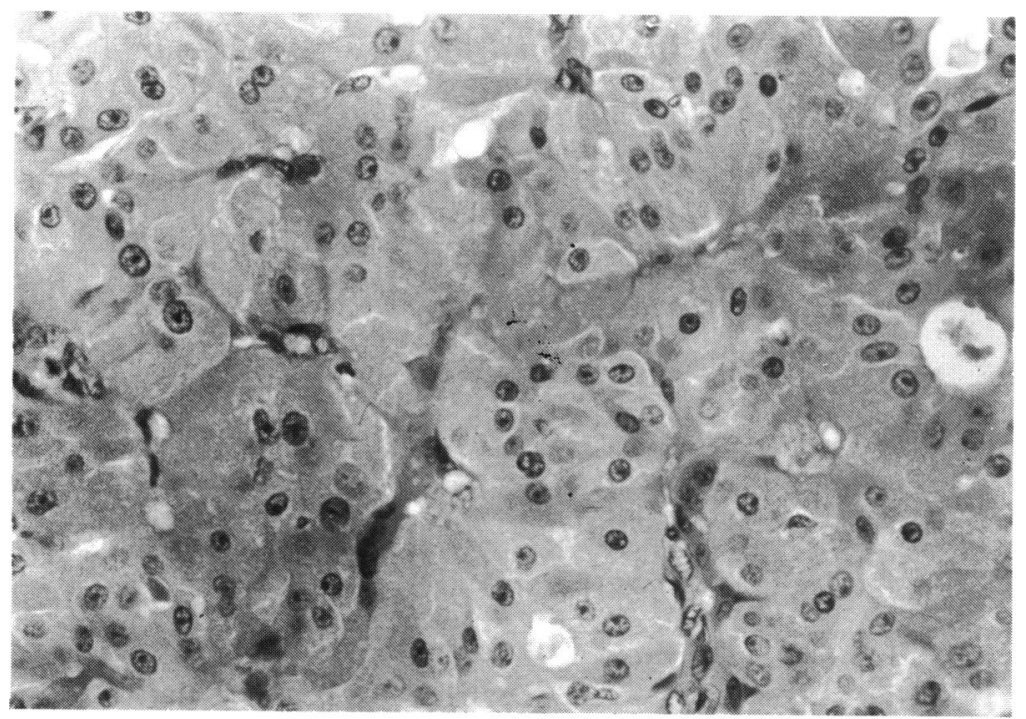

Fig. 6 Oncocytoma of eyelid. Trabecular pattern of tumour, with focal acini consisting of polygonal cells with eosinophilic granular cytoplasm and rounded regular nuclei, with prominent nucleoli. Haematoxylin and eosin. 
implying degenerative change, though the cells contain excessive numbers of mitochondria and few other organelles, which would tend to suggest increased cellular metabolism. Radnót resolves this paradox by suggesting that one is dealing with the proliferation of functionally impaired mitochondria, and this contention is supported by the pathological structure of the mitochondria on electron microscopy. Biggs and Font ${ }^{+}$consider that the lesions which they reported stemmed from oncocytic metaplasia of the ducts and acinar cells of adnexal lacrimal or salivary tissue. Our case may have arisen either from accessory lacrimal gland or from upper lacrimal canalicular tissue.
We thank Mr D S Thompson for kindly referring this case to us.

\section{References}

1 Hamperl H. Oncocyten und Geschwülste der Speicheldrüsen. Virchows Arch (Pathol Anat) 1931; 282: 724-36.

2 Radnót M. Aus Oncocyten bestehende adenomartige Hyperplasic in der Tränensackwand. Ophthalmologica 1941; 101: 95100 .

3 Böck J, Schlagenhauff K. Über das Vorkommen von Onkocyten in der menschlichen Tränendrüse. Z Augenheilkd 1938; 94: 244.

4 Biggs SL, Font RL. Oncocytic lesions of the caruncle and other ocular adnexac. Arch Ophthalmol 1977; 95: 474-8.

5 Radnót M, Lapis K. Ultrastructure of the caruncular oncocytoma. Ophthalmologica 1970; 161: 63-77.

Accepted for publication 16 October 1986. 